\title{
The Impact of Global Warming on the Global Climate
}

\author{
Abdulnaser S. Alseni* \\ *Public Authority for Applied Education and Training (PAAET), Kuwait, E
}

\begin{abstract}
Global warming is the gradual rise in environmental temperature due to depletion of the Ozone layer. The increase in the environmental temperatures is due to amplified rate of industrial development. In this case, most industries have contributed to the dangers associated with warming. The paper seeks to discuss global warming from various perspectives. It commences with an introduction highlighting the general information about the topic. The second part focuses on both natural and artificial causes while the last part discusses the effects on both humans and atmosphere.
\end{abstract}

Key Words: Atmosphere, Global Warming, Effluent, Troposphere, Greenhouse Effect

\section{INTRODUCTION}

Global warming refers to the increase in temperature within the atmosphere. Human activities and natural events are believed to contribute to the increase in average global temperature. Primarily, the major cause is the greenhouse gasses, which include carbon dioxide. As confirmed by the United States agency, the National Oceanic and Atmospheric Administration (NOAA), various indicators contribute to the increase or decrease in the global warming. The major pointers of the unequivocal climate system include the humidity, sea level, temperature over oceans, glaciers, snow cover, and temperature over land. According to Houghton, through observations, the global average air, temperatures, melting of snow and ice are above normal conditions (21). Although it is believed that global warming is caused by natural events, some of which may be inevitable by humans, the resulting greenhouse gasses have negative effects on the ecosystem.

\section{CAUSES}

To understand the causes of the greenhouse gasses, it is important to look for trends in global warming over a long period. Such an observation makes it easier for the researcher to know the factors contributing to the rise and fall of global temperatures. More so, the historical background of a continent or a country can help identify the real causes associated with the harmful event. For instance, north Atlantic was characterized with more frequent storminess during the 1980s and 1990s than in the previous decades (30). Many scholars, experts, and ecologists are expressing concerns about variations in the general weather of the earth. Some believe that a dangerous heating is taking place in the global climate, an issue that requires being addressed. Natural Causes of Global Warming. For centuries, the global climate has been changing. Volcanic explosions release carbon dioxide as well as emit aerosols, for example, sulphur dioxide, ash, or dust. Aerosols are in form of liquid or solids that are float in the air. They can also be carrying salt crystals, bacteria, soot, viruses, or dust. Aerosols can cause a little change in temperature through scattering the incoming radiations. During violent volcano eruptions, the vents discharge sulphur dioxide and ash particles to the stratosphere. The settling rate of the elements is determined by their size since the larger ones settle after few days. On the other hand, sulphur dioxide combines with water to sulphuric acid as well as sulphate particles. In the end, these constituents contribute to the formation of a thick layer of gasses that allow harmful electromagnetic rations to reach the earth (Zhong 483).Similarly, variation in solar radiation has contributed to global warming through the development of a very strong magnetic field that weakens the flow rate of gasses transmitting heat energy, hence leading to the formation of sunspots. Sunspots are dark spots on the sun's surface; therefore, their temperature is lower than that of the environment. The number of sunspots keeps on alternating after some years from maximum to minimum. Sun releases radiations during active periods of sunspots. Regions that are closer to the sunspots are brighter than those that are not due to the heat flow. Given this information, it is believed that the solar activity was reduced about 300 years ago.

The most witnessed climatic change that contributes to warming is El Nino-Southern Oscillation (ENSO). It involves swaying of the ocean system in the tropical areas of the Pacific Ocean causing alterations in weather patterns. The southeast trade winds blow from east to west. As a result, the cycle repeats after ever 3 to 10 years, making the warm water to flow to the east near the month of December. The fewer and less intense hurricanes that are experienced leads to more wind shear. Therefore, rainfall intensity becomes high in some tropical 
countries causing floods.Human causes of global warming. Growth in the number of industries has led to increased greenhouse gas emissions. For instance, during wastewater treatment and other industrial operations, greenhouse gasses are emitted into the atmosphere. The gasses include carbon dioxide, methane, among others (Holmen 2). Among them, carbon dioxide is the most plentiful. The gas is heavy, odourless, non-combustible and colourless. It is produced either indirectly because of fossil fuel burning, or directly due to respiratory processes living organisms contained in the wastewater. The latter case does not contribute to an increased carbon dioxide concentration to the atmosphere and its measurements may be negligible. Indirect emission is associated with wastewater transportation, various treatment processes, residual management, disposal, and pumping procedures. The main factor is the use of organic wastewater treatment, aerobic or anaerobic treatment technology, electricity used, and sludge processing.

\section{IMPACTS}

Greenhouse Effect. Following the high accumulation of gas residues in the lower zone of the atmosphere, it is possible for harmful sun radiations to traverse the Ozone layer. Within this troposphere complex, mixture of gasses known as greenhouse gasses keeps increasing. Consequently, when the sunlight reaches the earth, some of it is transformed to heat energy. In turn, greenhouse gasses trap some of the high temperature produced and retain it near the earth's surface. The world becomes heated up, and both plants and animals are faced with the challenge of the rise in temperature (Peters22).Rise in Sea Level. The global sea level has risen by about 7 inches. In regions of the Gulf of Mexico and East Cost, land has subsided, and the ocean is penetrating further towards the interior. As a result, the local sea level increase stands at an average of 8 inches, which is anticipated to rise. The major cause of this effect is high rate at which the ice is melting uphill and the expansion of seawater because of higher temperatures. The main risk is that the high tides and storm surges can combine with sea level subsidence and lead to increased flooding. In summary, it is clear that the sea level will continue to rise as the ocean waters persist to warm. Wildlife Extinction. As the sea, ocean, and land undergo rapid changes, both plants and animals that live in them disappear. According to the Intergovernmental Panel on Climate Changes (2014), many land and oceanic animals are migrating. The extreme warming has made the animals unable to adapt to climatic changes. Consequently, some oceanic animals have migrated to higher altitude regions to escape extreme heat. On the other hand, some animals have altered their traditional migration patterns and seasonal behaviour.
Indeed, some marine fish, reptiles, and amphibians migrated to cooler regions. In the long run, some animals have devised new survival mechanism such as hibernation to escape the harsh warming effects (Zhong 491).Polluted Ecosystem. Both the terrestrial and aquatic environments are in danger of pollution. The rise in environmental temperature leads to air pollution. Much of this greenhouse gasses is from the depletion of the Ozone layer. Their concentration rises with increase in air contamination from industrial and car pollution. The result is worsening health conditions of both plants and animals. Similarly, the pollution extends to the aquatic bodies, leading to acidic oceans. As the acidity increases, it poses health hazard to the oceanic life, including molluscs, fish, and planktons. As a result, most living organisms have died of environmental poisoning.

\section{CONCLUSION}

Global warming is the main challenge of the society today. Variations in climate are caused by both human activities and natural events. Natural causes include volcanic outbursts and variations in solar insolation. Artificial sources include industrial effluents due to industrialization. Without doubt, global warming can cause changes in climate in the next century. The rise in sea level and the associated increase in temperature make it difficult for both plants and animals to adapt to their natural habitats. In this case, some aquatic as well as land animals are migrating to escape the threat of global warming. Both air and water pollutions are the most influential as they have direct link to sources of industrial and motor vehicle effluent. Consequently, it leads to adverse effects to plants and animals. Therefore, socio-economic programs that recommend afforestation should be put in place to combat this harm. Correspondingly, educational reforms should lay emphasis on teaching the public about the wellbeing of plants, soil, water, animals, and air around them. To sum up, people should also be sensitized on human activities or environmental conditions which can benefit or impair the ecosystems.

\section{REFERENCE}

[1]. Holmen, Anders. "Direct Conversion of Methane to Fuels and Chemicals." Catalysis Today, vol. 142, no. 1, 2009, pp. 2-8.

[2]. Houghton, J T. Global Warming: The Complete Briefing. Cambridge: Cambridge University Press, 2009.

[3]. Lashof, Daniel A., and Dilip R. Ahuja. "Relative Contributions of Greenhouse Gas Emissions to Global Warming." Nature, vol. 344, no. 6266, 1990, pp. 529-531.

[4]. Peters, Robert L. "Effects of Global Warming on Forests." Forest Ecology and 
Management, vol. 35, no. 1-2, 1990, pp.13-

33.

[5]. Zhong, Cui-Xiang. "Causes of Global

Climate Change." International Journal of

Global Warming, vol. 10, no. 4, 2016, pp. 482-495. 